\title{
UPAYA KONSERVASI MINERAL DAN PROYEKSI MASA DEPAN PERTAMBANGAN TIMAH DI INDONESIA
}

\author{
Iskak Aji \\ Inspektur Tambang, Direktorat Teknik dan Lingkungan Mineral dan Batubara
}

\begin{abstract}
ABSTRAK
Konservasi mineral dan batubara merupakan salah satu aspek yang diamanatkan oleh UndangUndang Minerba untuk mewujudkan kaidah teknik pertambangan yang baik (Good Mining Practice). Konservasi minerba adalah upaya dalam rangka optimalisasi pengelolaan atau pemanfaatan sumber daya mineral dan batubara secara terukur, efisien, bertanggung jawab, dan berkelanjutan. Objek-objek yang menjadi target pengelolaan pelaksanaan konservasi mineral dan batubara sesuai Lampiran VII Kepmen ESDM No. 1827 K/30/MEM/2018 meliputi recovery penambangan, recovery pengolahan, batubara kualitas rendah, mineral kadar rendah, mineral Ikutan, sisa hasil pengolahan dan pemurnian, serta cadangan marginal. Kegiatan pertambangan timah di Indonesia berada di wilayah Provinsi Kepulauan Bangka Belitung dan Kepulauan Riau. Kegiatan ini dimulai sejak era kolonial Belanda yang ditandai dengan berdirinya "Banka Tin Winning Bedrijf" (BTW) di Belitung dan Singkep. Penambangan dilakukan oleh perusahaan swasta Belanda yaitu "Gemeeenschappelijke Mijnbouw Maatschappij Biliton" (GMB) dan "NV Singkep Tin Exploitatie Maatschappij" (NV SITEM). Kedua perusahaan ini berubah nama menjadi PT Timah, Tbk. Kegiatan pertambangan timah nasional mengalami pasang surut seiring dengan menipisnya cadangan timah karena eksploitasi yang sudah berlangsung lama dan perubahan terhadap kebutuhan saat ini maupun masa depan timah di dunia perindustrian. Untuk menjaga keberlanjutan kegiatan penambangannya, PT Timah, Tbk melakukan berbagai inisiatif diantaranya pelaksanaan konservasi dengan mengoptimalkan cadangan marginal, pemanfaatan sisa hasil pengolahan, penambangan mineral kadar rendah dan mineral ikutan. Saat ini PT Timah, Tbk mulai melakukan inventarisasi kembali cadangan timah yang sebelumnya ditinggalkan dan melakukan estimasi ulang untuk dikategorikan sebagai cadangan marginal. Potensi tambahan cadangan timah ini berasal dari bekas penambangan yang tidak tuntas maupun dari bekas penambangan tanpa ijin. Selain itu, PT. Timah, Tbk juga melakukan pendataan, inisiatif pengelolaan, dan rencana pemanfaatan untuk sisa hasil pengolahan, mineral kadar rendah dan mineral ikutan dengan aplikasi ketersedian teknologi saat ini. Beberapa upaya yang terus dikembangkan untuk tetap menjaga keberlanjutan industri pertambangan timah dan pengembangan timah primer adalah dengan pengembangan metode penambangan baru seperti borehole mining (BHM) dan inovasi metode penambangan yang sudah ada seperti cutter section dredges (CSD). Pelaksanaan hal-hal tersebut diatas adalah upaya nyata yang dilakukan oleh PT Timah, Tbk untuk melaksanakan konservasi mineral dan mendorong terwujudnya kaidah teknik pertambangan yang baik. Dengan pelaksanaan konservasi mineral dan dukungan dari seluruh stackholder, baik Pemerintah Daerah Provinsi Kepulauan Bangka Belitung dan PT. Timah, Tbk maka diproyeksikan kegiatan pertambangan timah nasional dapat terus bertahan dan berkelanjutan untuk menunjang industri timah nasional.
\end{abstract}

Kata Kunci: konservasi minerba, timah, cadangan marginal, sisa hasil pengolahan, mineral kadar rendah, mineral ikutan, pengelolaan

\begin{abstract}
Mineral and coal conservation is one of the aspects mandated by the Minerba Regulation to embodies the principles of Good Mining Practice. Mineral and coal conservation is an effort to optimize the management or utilization of mineral and coal resources in a measured, efficient, responsible and sustainable. Objects that are targeted for mineral and coal conservation in
\end{abstract}


accordance with Attachment VII of the Minister of Energy and Mineral Resources Decree No. 1827 $K$ / 30 / MEM / 2018 comprise of restoration mining recovery, processing recovery, low quality coal, low grade minerals, gangue minerals, residues from processing and refining, and marginal reserves. Tin mining activities in Indonesia are mainly in the provinces of the Bangka Belitung Islands and Riau Islands. This activity began in the Dutch colonial era marked by the establishment of "Banka Tin Winning Bedrijf" (BTW) in Belitung and Singkep. Mining is carried out by a Dutch private company, "Gemeeenschappelijke Mijnbouw Maatschappij Biliton" (GMB) and "NV Singkep Tin Exploitatie Maatschappij" (NV SITEM). These two companies then merged into PT Timah, Tbk. Tin mining activities in Indonesia experienced the ups and downs through the depletion of tin reserve due to lifelong exploitation and changes in the current needs and the future of tin in the industrial world. To ensure the sustainability of its mining activities, PT Timah, Tbk has conducted a variety of initiatives such as conserving by optimizing marginal reserve, utilizing the residue of processed products, mining low grade minerals and accompanying gangue minerals. Currently PT Timah, Tbk starts to carry out an inventory of the previously abandoned reserves and re-estimates to be categorized as marginal reserves. This potential additional on tin reserves are comes from mines that are incomplete or from ex-mining activity without permits. In addition, PT. Timah, Tbk also conducts data collection, management innitative, and utilization plans for processing residues, low grade minerals and gangue minerals with current technology applications available. Some efforts that are continually being developed for the sustainable development of the tin mining industry and primary tin development are by developing new mining methods such as borehole mining (BHM) and innovate in existing mining methods such as cutter section dredges (CSD). The implementation of the above is a real effort made by PT Timah, Tbk to carry out mineral conservation and encourage the realization of good mining practice. With mineral conservation and the support from the stockholders, the Bangka Belitung Islands Provincial Government and PT. Timah, Tbk, it is projected that tin mining activities in Indonesia can be maintained and sustainable to support the national tin industry.

Key Word: Coal and mineral Conservation minerba, tin, marginal reserve, residual of processing and refining, Low grade mineral, gangue mineral,management

\section{A. PENDAHULUAN}

Mineral dan Batubara merupakan sumber daya alam yang tidak dapat diperbaharui yang keterdapatannya secara geologi hanya pada lokasi tertentu dan terbatas. Indonesia merupakan salah satu negara yang relatif kaya akan sumber daya alam mineral dan batubara namun kuantitas maupun kualitasnya terbatas. Oleh sebab itu diperlukan adanya pengelolaan yang optimal agar dapat dipergunakan sebaik mungkin untuk kemakmuran dan kesejahteraan rakyat sesuai dengan amanat UUD tahun 1945 pasal 33 ayat (3). Sumber Daya dan Cadangan Mineral dan Batubara harus dikelola berdasarkan asas manfaat, keadilan, keseimbangan, berkelanjutan, dan berwawasan lingkungan. Berdasarkan data dari Badan Geologi, cadangan nasional Indonesia untuk mineral logam tahun 2018 mengalami kenaikan dibandingkan dengan tahun 2017 terkecuali untuk komoditas emas, sedangkan untuk cadangan batubara juga mengalami kenaikan. Data lengkap cadangan nasional dapat dilihat pada Gambar 1, Gambar 2, Gambar 3, dan Gambar 4 di bawah ini.

Konservasi mineral dan batubara merupakan salah satu aspek yang diamanatkan oleh UndangUndang No. 4 Tahun 2009 Tentang Pertambangan Mineral dan Batubara yaitu kewajiban untuk mewujudkan kaidah teknik pertambangan yang baik (Good Mining Practice). Konservasi mineral dan batubara merupakan upaya dalam rangka optimalisasi pengelolaan atau pemanfaatan sumber daya mineral dan batubara secara terukur, efisien, bertanggung jawab, dan berkelanjutan yang wajib dilaksanakan. Objek-objek konservasi yang menjadi target pengelolaan dan pelaksanaan konservasi mineral dan batubara telah tertuang dalam Lampiran VII Kepmen ESDM No. 1827 K/30/MEM/2018 yaitu, recovery penambangan, recovery pengolahan, batubara kualitas rendah, mineral kadar rendah, mineral ikutan, cadangan marginal dan sisa hasil pengolahan. PT Timah Tbk 
sebagai pelaku usaha pertambangan khususnya komoditas timah yang berada di wilayah Kepulauan Bangka Belitung dan Kepulauan Riau telah berupaya untuk menerapkan pengelolaan konservasi mineral.

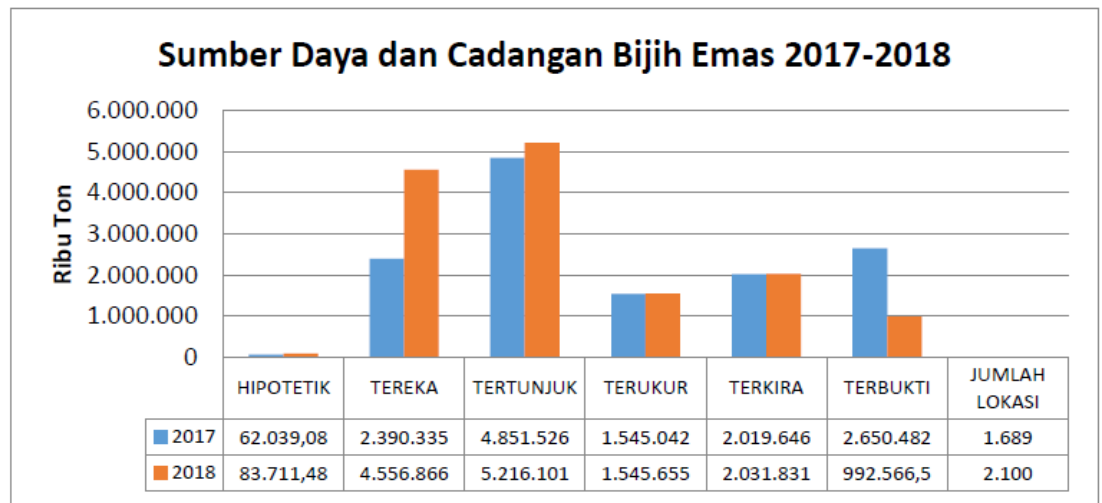

Sumber: Badan Geologi (2018)

Gambar 1. Grafik Pemutakhiran Sumber Daya dan Cadangan Bijih Emas Primer Tahun 2017-2018

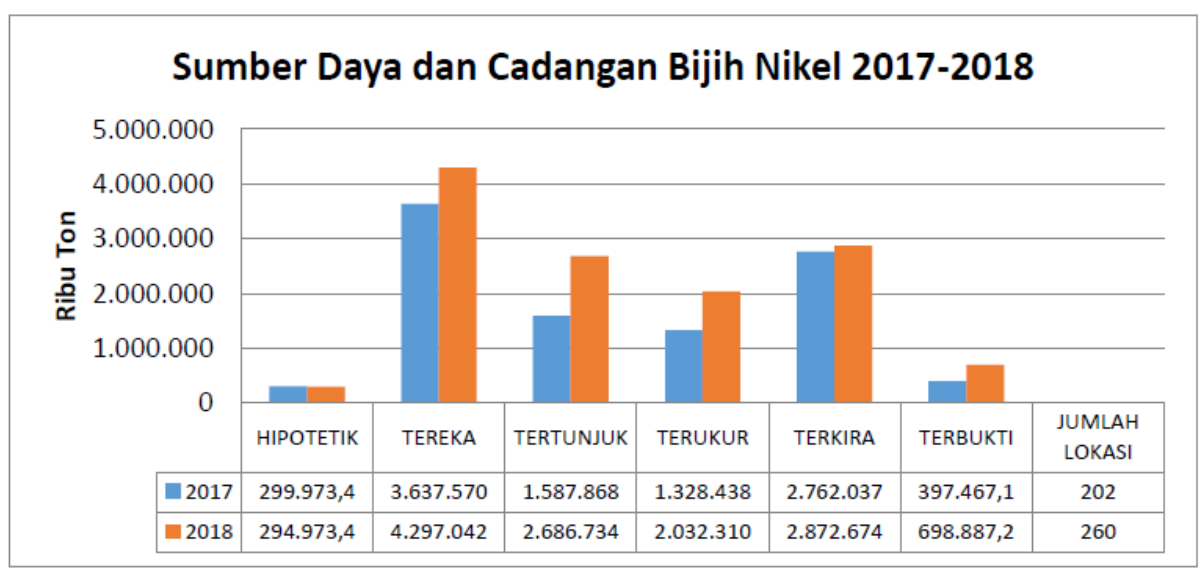

Sumber: Badan Geologi (2018)

Gambar 2. Grafik Pemutakhiran Sumber Daya dan Cadangan Bijih Nikel Tahun 2017-2018

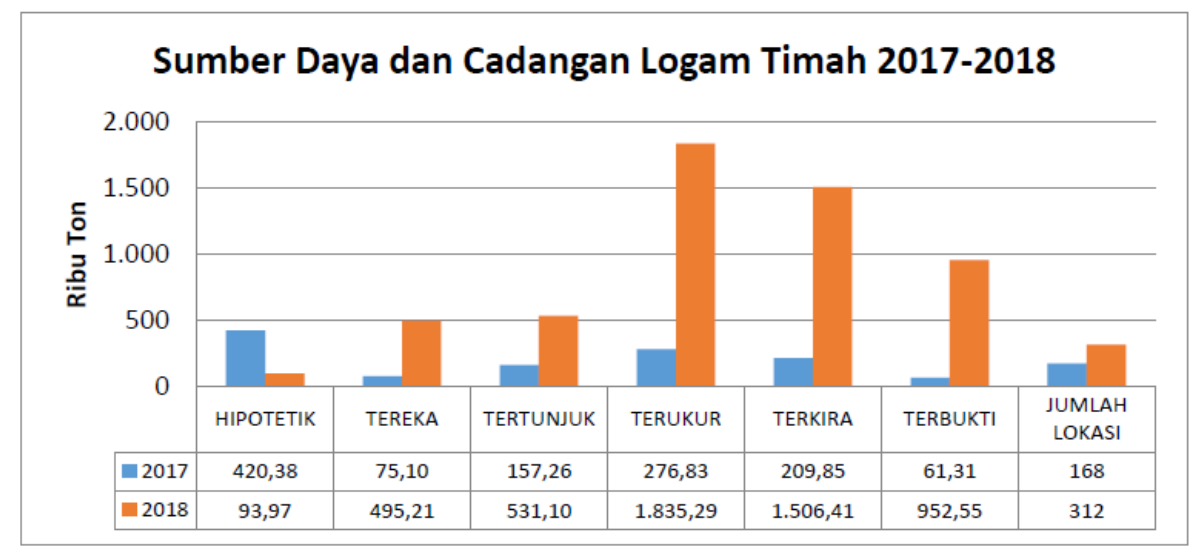

Sumber: Badan Geologi (2018)

Gambar 3. Grafik Pemutakhiran Sumber Daya dan Cadangan Logam Timah Tahun 2017-2018 


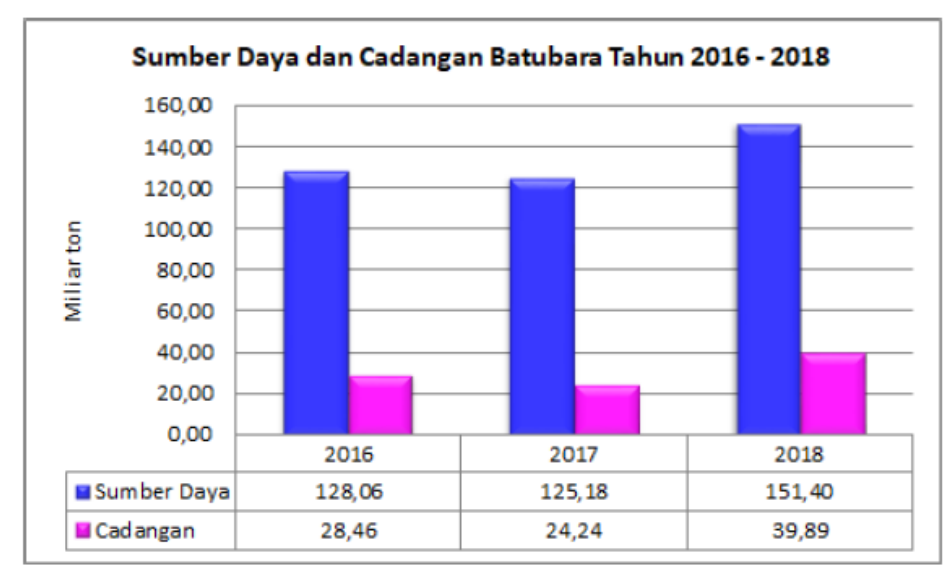

Sumber: Badan Geologi (2018)

Gambar 4. Grafik Pemutakhiran Sumber Daya dan Cadangan Batubara Tahun 2016-2018

Beberapa kebijakan telah dibuat untuk mendukung upaya pelaksanaan konservasi diantaranya adalah dengan mengoptimalkan cadangan marginal, sisa hasil pengolahan, mineral kadar rendah, dan mineral ikutan termasuk juga upaya pengembangan timah primer yang selama ini ditinggalkan oleh PT timah Tbk. Upaya-upaya tersebut merupakan langkah nyata PT Timah untuk mendorong teruwujudnya kaidah teknik pertambangan yang baik khususnya aspek konservasi mineral dan juga untuk mempertahankan proses bisnis PT Timah guna menunjang industri timah nasional. Dengan adanya upaya penerapan konservasi, terjadi peningkatan cadangan timah secara signifikan, sehingga nilai investasi PT Timah juga menjadi meningkat. Harapan dari penysusunan makalah ini agar seluruh pelaku usaha pertambangan dapat mengupayakan penerapan konservasi mineral dan batubara yaitu dengan mengoptimalkan pengelolaan dan atau pemanfaatan sumber daya mineral dan batubara secara terukur, efisien, bertanggung jawab, dan berkelanjutan sehingga cadangan nasional dapat meningkat dan ketahanan nasioanal terhadap sumber daya alam untuk mendukung industri nasional khususnya logam timah dapat terwujud. Metodologi penelitian dilakukan dengan pengumpulan data dari laporan-laporan berkala tahunan dan triwulanan dan hasil pengawasan dilapangan.

\section{B. UPAYA PENERAPAN KONSERVASI MINERAL DAN BATUBARA}

Dengan terbitnya Peraturan Menteri ESDM No. 26 Tahun 2018 Tentang Pelaksanaan Kaidah Pertambangan yang Baik dan Pengawasan Pertambangan Mineral dan Batubara, para pemegang Izin Usaha Pertambangan (IUP) baik IUP/IUPK Eksplorasi, IUP/IUPK Operasi Produksi maupun IUP Operasi Produksi Khusus Pengolahan dan/atau Pemurnian wajib untuk melaksanakan kaidah teknik pertambangan yang baik dimana salah satu aspeknya adalah konservasi mineral dan batubara. Pedoman pelaksanaan konservasi mineral dan batubara telah ditetapkan dalam Lampiran VII Kepmen ESDM No. 1827 K/30/MEM/2018 Tahun 2018 dengan ruang lingkup objekobjeknya sebagai berikut:

1. Perencanaan dan Pelaksanaan Recovery penambangan;

2. Perencanaan dan Pelaksanaan Recovery pengelolaan;

3. Pengelolaan Batubara Kualitas Rendah dan Mineral Kadar Rendah, Mineral Ikutan, Sisa Hasil Pengolahan dan Pemurnian, dan Cadangan Marginal;

4. Pemanfaatan Batubara Kualitas Rendah dan Mineral Kadar Rendah, Mineral Ikutan, dan Cadangan Marginal; dan,

5. Pendataan Cadangan Tidak Tertambang, serta Sisa Hasil Pengolahan dan Pemurnian. 
Pemerintah dalam hal ini Subdit Konservasi Mineral dan Batubara Direktorat Teknik dan Lingkungan Direktorat Jenderal Mineral dan Batubara telah melakukan sosialisasi terhadap pedoman pelaksanaan konservasi mineral dan batubara selama tahun 2018 melalui kegiatan bimbingan teknis maupun pembinaan dan pengawasan yang dilakukan oleh Inspektur Tambang dengan maksud dan tujuan agar seluruh pelaku usaha dapat memahami dan melaksanakan kewajiban pelaksanaan konsevasi minerba.

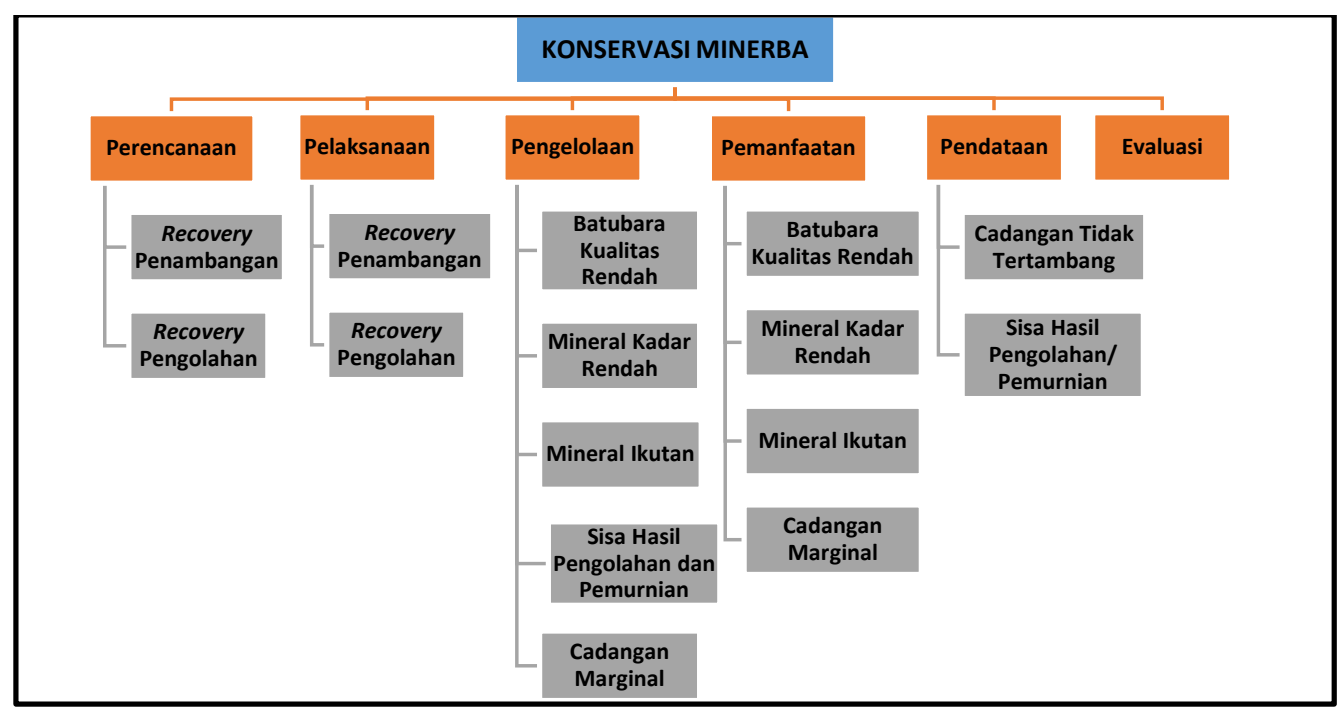

Gambar 5. Ruang Lingkup Dan Objek-Objek Konservasi Mineral dan Batubara

Salah satu ukuran untuk mengetahui apakah pelaksanaan konservasi mineral dan batubara telah dilaksanakan oleh seluruh pelaku usaha pertambangan adalah melalui laporan dan evaluasi. Pelaksanaan penerapan konservasi mineral dan batubara disampaikan kepada Pemerintah melalui laporan berkala konservasi secara triwulan paling lambat 30 hari kalender setelah berakhirnya triwulan. Format pelaporan berkala konservasi telah tertuang dalam Lampiran VIII M Kepmen ESDM No. 1806 K/30/MEM/2018 Tahun 2018. Melalui laporan berkala konservasi, Pemerintah dapat melakukan evaluasi seberapa optimalnya penerapan konservasi yang telah dilakukan oleh pelaku usaha pertambangan, termasuk juga tingkat kepatuhan pelaporan berkala. Dari hasil evaluasi pada tahun 2019, terdapat beberapa perusahaan yang belum pernah menyampaikan laporan berkala konservasi. Adapun langkah yang diambil oleh Pemerintah adalah dengan memberikan surat peringatan, dan apabila belum juga menyampaikan laporan maka Pemerintah akan menghentikan segala bentuk perijinan aspek teknik dan lingkungan terhadap perusahaan tersebut. Pemerintah menargetkan dapat mensosialisasikan pemahaman terkait dengan upaya penerapan konservasi dapat selesai di tahun 2018 dan 2019. Harapannya di tahun 2020 dan seterusnya, Pemerintah akan memberikan penghargaan dan insentif bagi setiap pelaku usaha pertambangan yang telah menerapkan konservasi mineral dan batubara secara optimal. Konservasi mineral dan batubara saat ini juga menjadi salah satu aspek evaluasi penting terhadap beberapa kebijakan Pemerintah, salah satunya adalah dalam pertimbangan perpanjangan Izin Usaha Jasa Pertambangan. Kedepannya, kebijakan berkaitan konservasi mineral dan batubara akan tetap dijadikan usulan dengan dukungan data-data laporan dan hasil evaluasi pembinaan dan pengawasan di lapangan.

\section{PERTAMBANGAN DAN KONSERVASI TIMAH OLEH PT TIMAH, TBK}

Pada masa pemerintahan Belanda di Indonesia, usaha pertambangan timah dikelola oleh tiga perusahaan yaitu: (1) Bangka Tin Winning Bedrijf (BTW), badan usaha yang dimiliki pemerintah Belanda; (2) Gemeenschappelijke Mijnbow Maatschappij Biliton (GMB); dan (3) NV. Singkep Tin Explitatie Maatschappij (NV. SITEM), badan usaha milik swasta Belanda yang berada di Pulau 
Belitung dan Singkep. Pada periode tahun 1953-1958, setelah Kemerdekaan Indonesia, ketiga perusahaan tersebut diambil alih oleh Pemerintah Indonesia dan diubah menjadi perusahaan negara. Pada tahun 1961 dibentuk Badan Pimpinan Umum Perusahaan Tambang-Tambang Timah Negara (BPUPN Tambang Timah), dan selanjutnya pada tahun 1968 ketiga perusahaan tersebut dilebur menjadi satu perusahaan dengan nama Perusahaan Negara (PN) Tambang Timah, yang kemudian dikenal dengan PT. Timah Tbk. PT. Timah, Tbk memiliki visi perusahaan yakni menjadi perusahaan pertambangan terkemuka di dunia yang ramah lingkungan dengan meningkatkan produktifitas operasi produksi guna pemenuhan kebutuhan timah nasional maupun internasional.

Berdasarkan data USGS tahun 2017-2018, Indonesia merupakan produsen dan eksportir timah terbesar ke-2 di dunia melalui PT Timah Tbk.

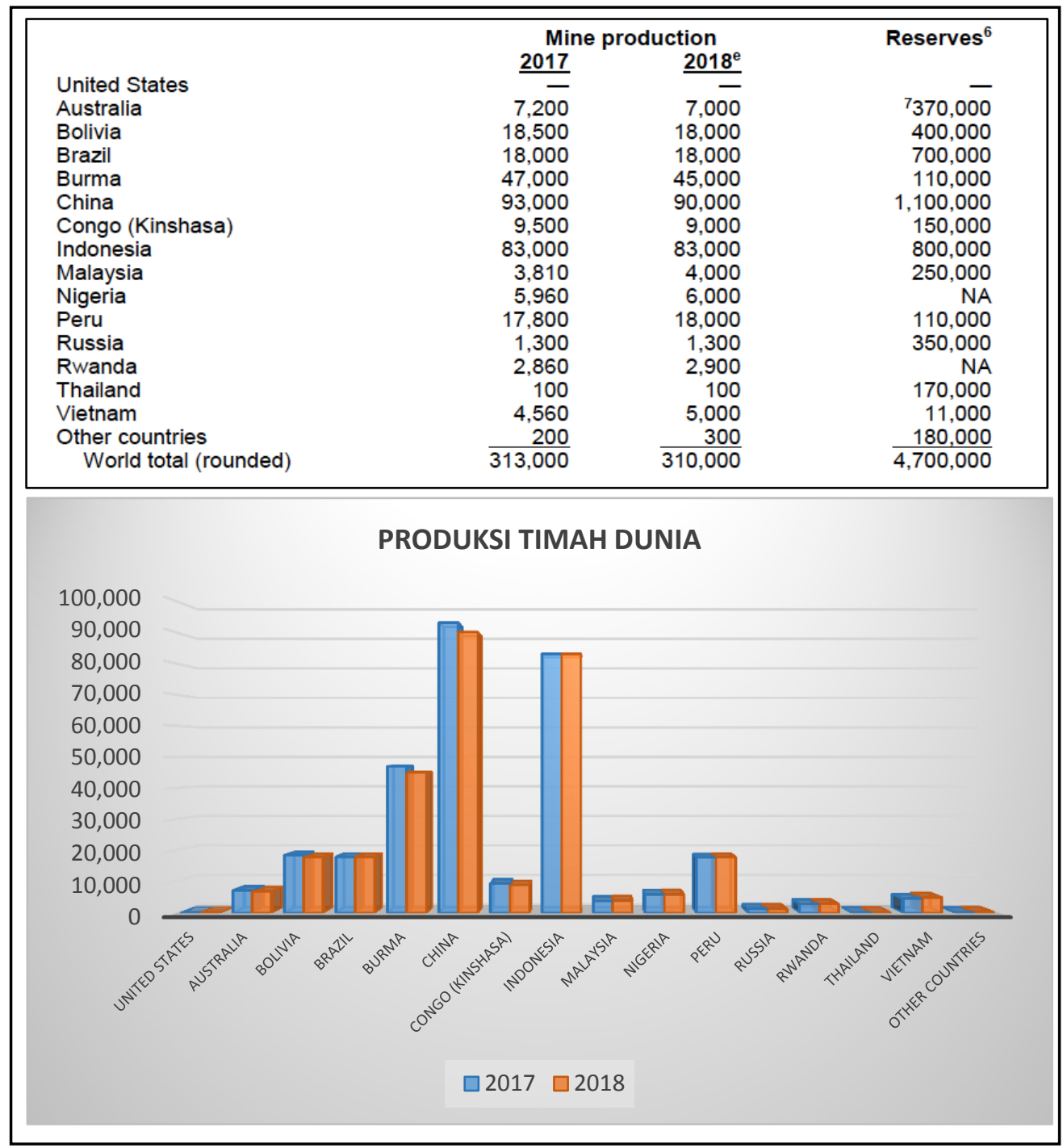

Sumber: USGS (2019), diolah

Gambar 6. Produsen Timah di Dunia

Rencana produksi PT Timah, Tbk tahun 2019 adalah sebesar 79.000 Mt dengan rincian 68.300 Mt dari Kepulauan Bangka Belitung dan 10.700 Mt dari Kepulauan Riau. Jumlah produksi ini merupakan lebih dari 95\% produksi logam timah Nasional (Sumber: Kementerian ESDM).

Saat ini PT Timah Tbk menerapkan beberapa kebijakan dan program untuk meningkatkan produksi dan mendukung upaya penerapan konservasi mineral, diantaranya adalah sebagai berikut: 
1. Program pengamanan asset dengan menyelamatkan bijih yang diambil oleh kegiatan penambangan illegal termasuk penambangan Bijih timah primer

2. Program peningkatan recovery penambangan melalui pengelolaan material sisa hasil pengolahan

3. Program peningkatan produksi penambangan di darat maupun di laut sebagai bentuk pengelolaan dan pemanfaatan cadangan marginal timah

4. Program kemitraan dan jasa pertambangan melalui skema kerjasama dengan mitra untuk penambangan di darat maupun di laut

5. Program penambangan integrasi melalui peningkatan kapasitas produksi bijih dengan menyewa alat penambangan maupun skema kerjasama dengan IUP OPK olah murni yang terintegrasi termasuk alat untuk metode penambangan bore hole mining dan Cutter Suction Dredge (CSD).

Sejak tahun 2008 penambangan ilegal mulai banyak merambah wilayah PT Timah Tbk yang mengakibatkan kerugian negara yang cukup besar. Untuk mengatasi hal tersebut, Pemerintah mengeluarkan Peraturan Menteri untuk mengakomodir para penambang illegal di wilayah PT Timah, Tbk agar memiliki ijin usaha jasa penambangan dengan skema kemitraan. Permen ESDM No. 24 Tahun 2012 tentang Perubahan Atas Peraturan Menteri Energi Dan Sumber Daya Mineral Nomor 28 Tahun 2009 tentang Penyelenggaraan Usaha Jasa Pertambangan Mineral Dan Batubara menyatakan bahwa dalam rangka pengembangan dan pemberdayaan masyarakat setempat, optimalisasi pemanfaatan, dan konservasi sumber daya mineral jenis timah aluvial, pemegang IUP atau IUPK yang berbentuk BUMN atau BUMD dalam pelaksanaan kegiatan penggalian endapan timah aluvial, dapat menyerahkan pekerjaannya kepada Perusahaan Jasa Pertambangan Lokal dan/ atau masyarakat sekitar tambang melalui program kemitraan, setelah mendapatkan persetujuan Menteri. Peraturan Menteri tersebut saat ini digantikan oleh Permen ESDM No. 11 Tahun 2018 dalam rangka penyederhanaan perijinan.

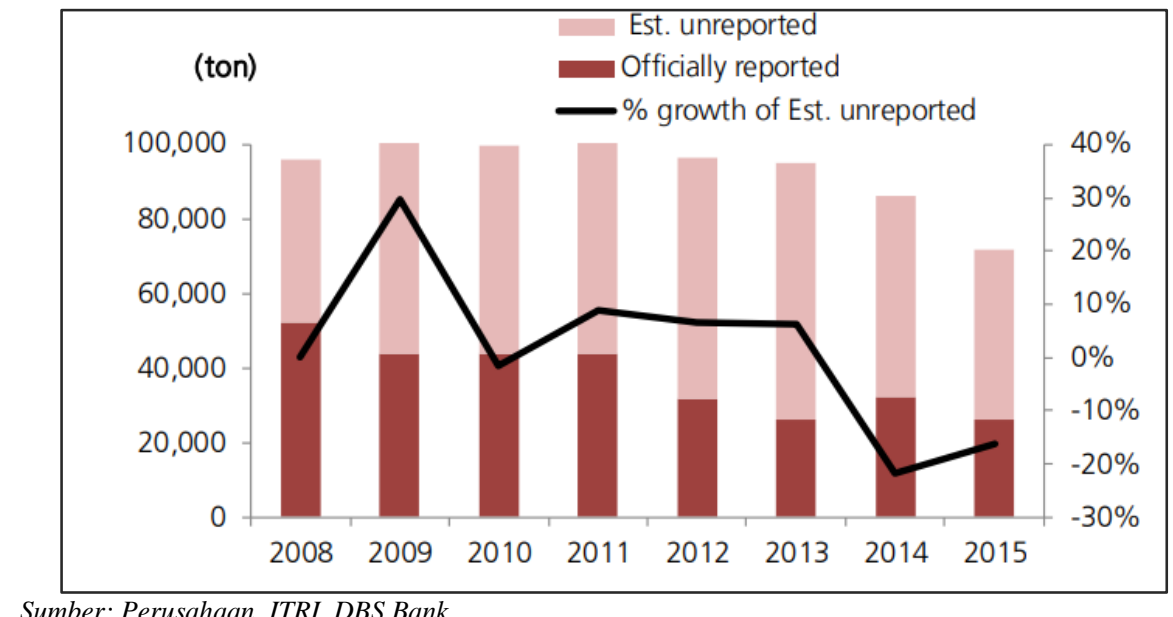

Gambar 7. Grafik Perbandingan Produksi Timah yang terlaporkan dengan Estimasi Produksi Ilegal Mining

Saat ini PT. Timah, Tbk mulai melakukan inventarisasi kembali cadangan timah yang sebelumnya ditinggalkan dan melakukan estimasi ulang untuk dikategorikan sebagai cadangan marginal. Potensi tambahan cadangan timah ini berasal dari bekas penambangan yang tidak tuntas maupun dari bekas penambangan tanpa ijin. Selain itu, PT. Timah, Tbk juga melakukan pendataan, inisiatif pengelolaan, dan rencana pemanfaatan untuk sisa hasil pengolahan, mineral kadar rendah dan mineral ikutan dengan aplikasi ketersedian teknologi saat ini. Beberapa upaya yang terus dikembangkan untuk tetap menjaga keberlanjutan industri pertambangan timah dan pengembangan timah primer adalah dengan pengembangan metode penambangan baru seperti borehole mining (BHM) dan inovasi metode penambangan yang sudah ada seperti cutter section dredges (CSD). 
Tabel 1. Tambahan Neraca Sumberdaya dan Cadangan Timah Primer Area Kep. Bangka Belitung

\begin{tabular}{|l|c|}
\hline Total Sumberdaya & Total Cadangan \\
\hline \multicolumn{2}{|c|}{ (Ton Sn) } \\
\hline \multicolumn{2}{|c|}{131,750} \\
Sumber: PT Timah, Tbk, Kemeterian ESDM \\
\hline
\end{tabular}

Kegiatan penambangan PT. Timah, Tbk dibagi menjadi dua unit penambangan yaitu unit penambangan darat dan unit penambangan laut. Pelaksanaan Tambang Darat PT TIMAH Tbk dilaksanakan oleh Satuan Kerja Unit Produksi Darat Bangka dan Unit Produksi Belitung. Berdasarkan tata cara dan tata laksana penambangan timah darat di Lingkungan PT TIMAH Tbk, sistem pertambangan untuk bijih galian timah dibagi berdasarkan objek tambang terbagi menjadi empat (4) kelas tambang yaitu Tambang Besar (TB), Tambang Semprot (TS), Tambang Skala Kecil (TK) dan Tambang Ponton Isap Darat (TPID).

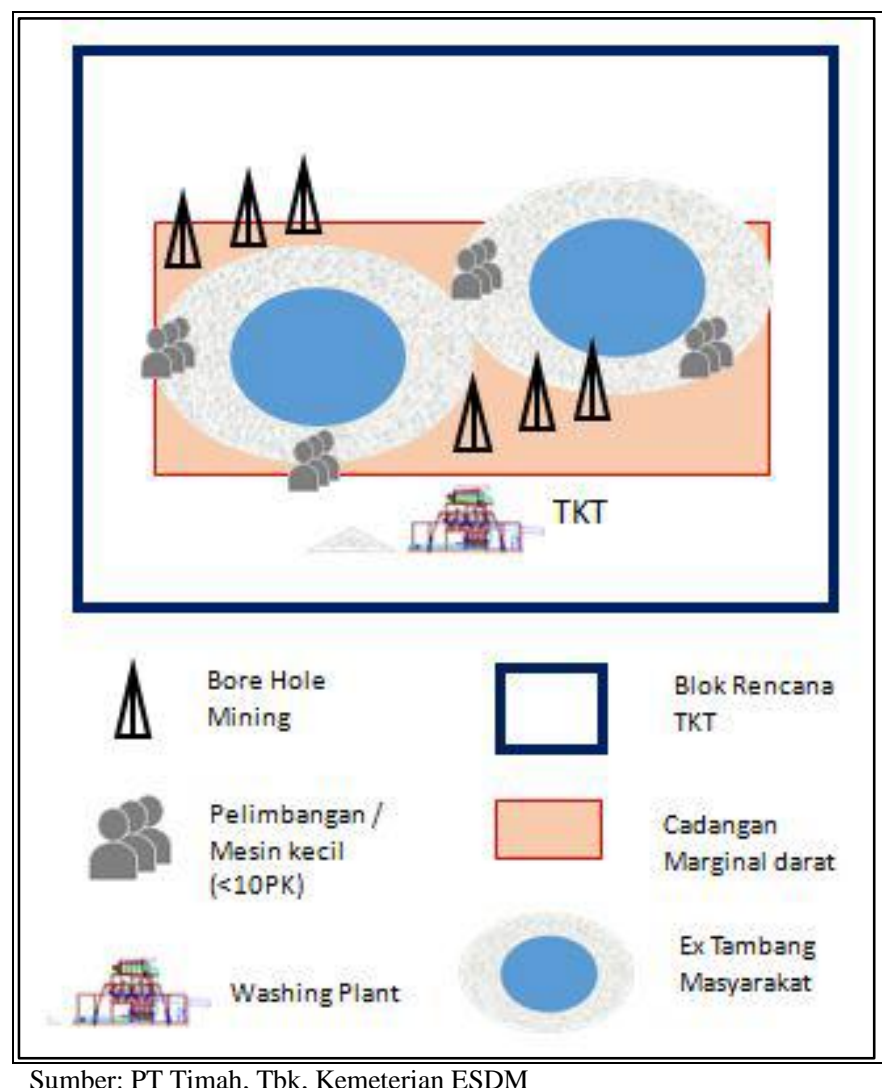

Gambar 8. Skema Penambangan Kecil Terintegrasi

Dalam Rangka Pengelolaan Cadangan Marginal

Secara umum operasi penambangan unit laut dilakukan dengan mengoperasikan sarana penambangan dengan menggunakan alat BWD (bucket wheel dredger), Kapal Keruk (bucket line dredger) dan Kapal Isap Produksi (KIP). Pada Kapal Isap Produksi penggalian dapat dilakukan tanpa melakukan pengupasan overburden terlebih dahulu, yaitu penggalian langsung menuju lapisan ore dengan metode Borehole Mining (BHM). Metode penggalian BHM adalah selective mining, dimana BHM dapat menambang pada area grade timah yang masih bernilai ekonomis. Area-area yang ditambang olah BHM tadinya tidak bernilai ekonomis apabila ditambang dengan menggunakan Kapal Keruk maupun Kapal Isap Produksi. Dengan adanya inovasi peralatan dengan menggunakan BHM area-area cadangan marginal yang tadinya belum bernilai ekonomis untuk dilakukan penambangan maka akan menjadi bernilai ekonomis. 


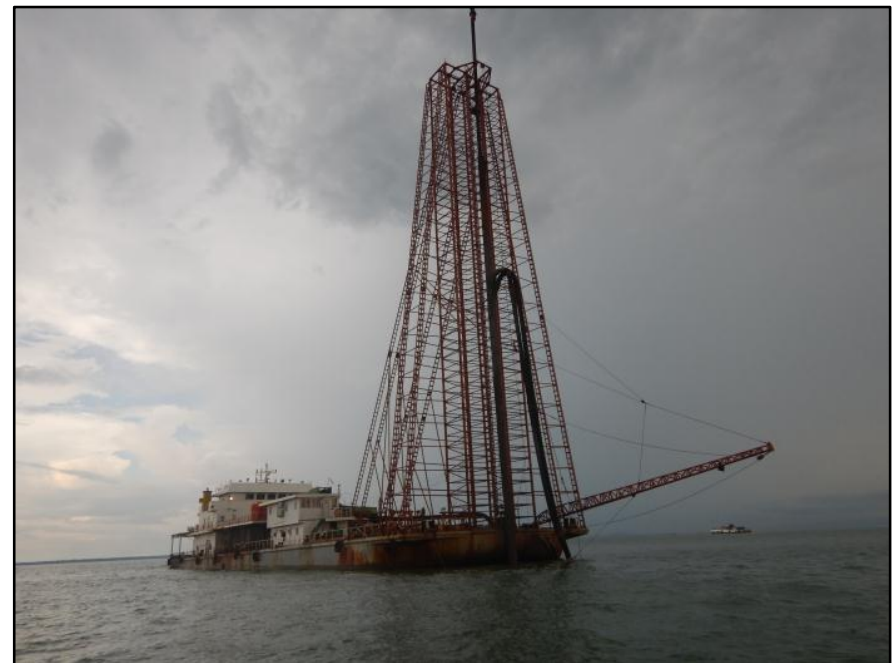

Gambar 9. Peralatan Bore Hole Mining untuk unit penambangan laut

Cutter Suction Dredge (CSD) merupakan bagian metode penambangan unit laut dengan melakukan modifikasi dan improvisasi dimana alat tersebut sebelumnya hanya digunakan sebagai alat untuk mengupas lapisan tanah penutup (Overburden). Modifikasi yang dilakukan adalah dengan membangun alat pencucian sebagai alat pengolahan untuk memisahkan mineral timah berharga berada di darat. Dengan adanya CSD, cadangan marginal timah yang berada pada lokasi kedalaman $\pm 20 \mathrm{~m}$ yang sebelumnya tidak dapat dilakukan penambangan menggunakan Kapal Keruk dan Kapal Isap Produksi menjadi dapat termanfaatkan.

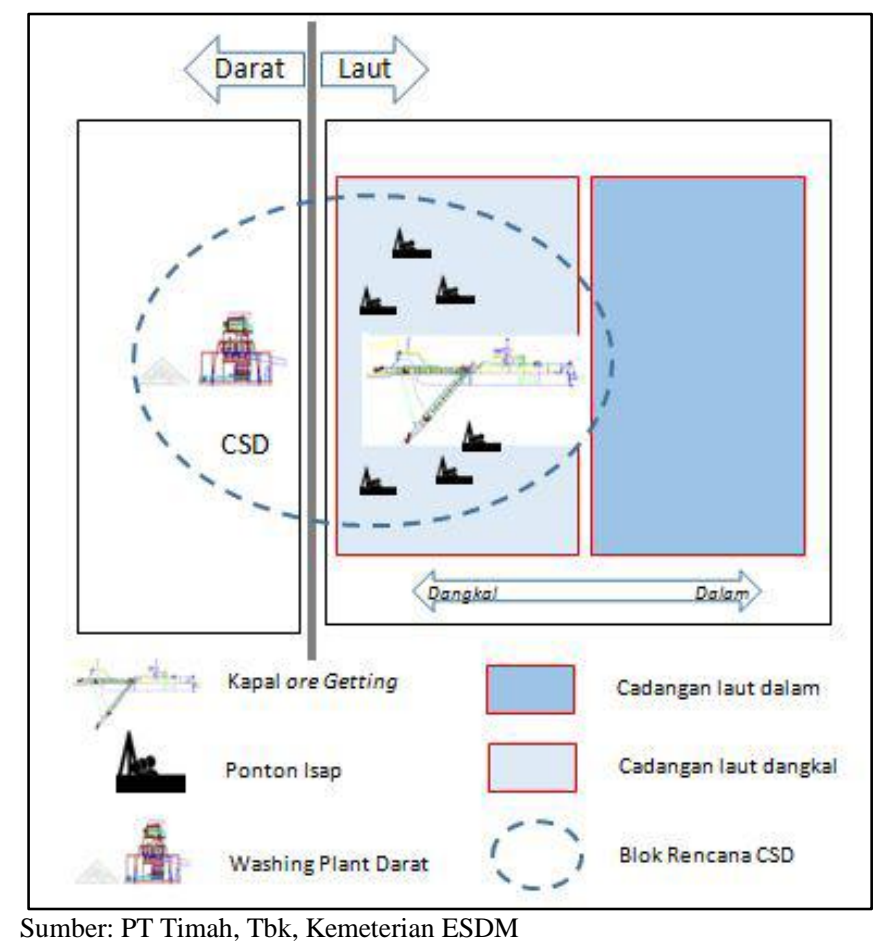

Gambar 10. Skema Penambangan Cadangan Laut Dangkal dengan CSD

Pengelolaan dan pemanfaatan mineral ikutan merupakan amanat dari Lampiran VII Kepmen ESDM No, 1827 K/30/MEM/2018 tentang Pedoman Pelaksanaan Konservasi. Berdasarkan data ekplorasi PT Timah, Tbk terdapat beberapa kandungan mineral ikutan yang saat ini masih dalam proses estimasi sumberdaya (lihat Tabel 2 dibawah). 
Tabel 2. Estimasi Potensi Mineral Ikutan Timah Kep, Bangka Belitung

\begin{tabular}{|l|c|c|c|}
\hline MIT & Volume $\left(\mathbf{m}^{\mathbf{3}}\right)$ & Kadar $\left(\mathbf{k g} / \mathbf{m}^{\mathbf{3}}\right)$ & Tonase (ton) \\
\hline Ilmenite & 3.547 .159 .275 & 0,104 & 367.500 \\
\hline Monazite & 3.547 .159 .275 & 0,006 & 19.900 \\
\hline Zircon & 3.547 .159 .275 & 0,041 & 145.800 \\
\hline
\end{tabular}

Sumber: PT Timah, Tbk, Kemeterian ESDM

Mineral ikutan timah pada bijih timah yang telah tertambang, dilakukan pemisahan menggunakan High Tension Separatior (HTS) dan Magnetic Separator (MS) di Pusat Pencucian Bijih Timah (PPBT) baik di wilayah Bangka Belitung (Muntok) maupun di wilayah Kep. Riau dan Riau (Kondur). Hasil pengelolan mineral ikutan yang tertambang dalam hal ini yang didominasi ilmenite belum dapat dimafaatkan sehingga sampai saat ini masih disimpan secara khusus di dalam stockpile. Jumlah tonase mineral ikutan akan semakin meningkat dari tahun ke tahun namun saat ini masih belum dapat termanfaatan dan pengawasan penyimpanannya dilakukan oleh Bapeten. Project pemanfaatan mineral ikutan masih terus dilakukan di REE Plant Tanjung Ular.

Tabel 4. Inventory Mineral Ikutan PT Timah Tbk Unit Metalurgi Muntok

\begin{tabular}{|c|c|c|c|c|c|c|c|c|c|c|c|c|c|}
\hline \multirow{2}{*}{ Bulan } & \multirow{2}{*}{ Mutasi } & \multicolumn{2}{|c|}{ IImenit HG } & \multicolumn{2}{|c|}{ IImenit LG } & \multicolumn{2}{|c|}{ Monazite HG } & \multicolumn{2}{|c|}{ Monazite LG } & \multicolumn{2}{|c|}{ Xenotime } & \multicolumn{2}{|c|}{ Zircon HG } \\
\hline & & Ore Mineral & Con Mineral & Ore Mineral & Con Mineral & Ore Mineral & Con Mineral & Ore Mineral & Con Mineral & Ore Mineral & Con Mineral & Ore Mineral & Con Mineral \\
\hline \multirow{4}{*}{ TOTAL } & Stock Awal (Kg) & $2,915,719$ & $2,500,694$ & $1,438,714$ & 518,863 & 457,741 & 358,139 & 630,590 & 243,202 & 89 & 58 & 577,051 & 520,521 \\
\hline & Produksi $(\mathrm{Kg})$ & 766,114 & 687,192 & & & 209,526 & 177,739 & 27,491 & 21,349 & - & - & 198,506 & 164,594 \\
\hline & Pengeluaran $(\mathrm{Kg})$ & 203 & 175.15 & - & - & 1,014 & 893 & 503 & 205 & - & - & 28 & 26.61 \\
\hline & Stock Akhir (Kg) & $3,681,630$ & $3,187,711$ & $1,438,714$ & 518,863 & 666,253 & 534,985 & 657,578 & 264,346 & 89 & 58 & 775,529 & 685,088 \\
\hline
\end{tabular}

Sumber: PT Timah Tbk, Kementrian ESDM

Saat ini produksi timah dalam negeri baru mampu menghasilkan produk-produk hulu dan sudah saatnya industri timah Indonesia mengantisipasi meningkatnya permintaan dalam negeri atas produk-produk hilir industri timah seiring dengan tumbuhnya perekonomian nasional. Meski Indonesia merupakan produsen utama timah dunia yang mengusai lebih dari $30 \%$ produksi timah dunia setiap tahunnya, namun cadangan timah memiliki jumlah dan berada pada lokasi terbatas. Saat ini cadangan timah yang dimiliki Indonesia sebesar 900.000 ton (Sumber: Badan Geologi, 2018), dengan asumsi produksi penambangan hingga 90.000 ton setiap tahunnya (Kementrian ESDM), maka cadangan timah yang dimiliki saat ini diprediksi 10 hingga 12 tahun ke depan akan habis apabila tidak ada penemuan cadangan baru. Oleh sebab itu sudah saatnya hilirisasi industri komoditas timah dilakukan untuk mendukung ketahanan nasional khususnya dari sektor pertambangan timah.

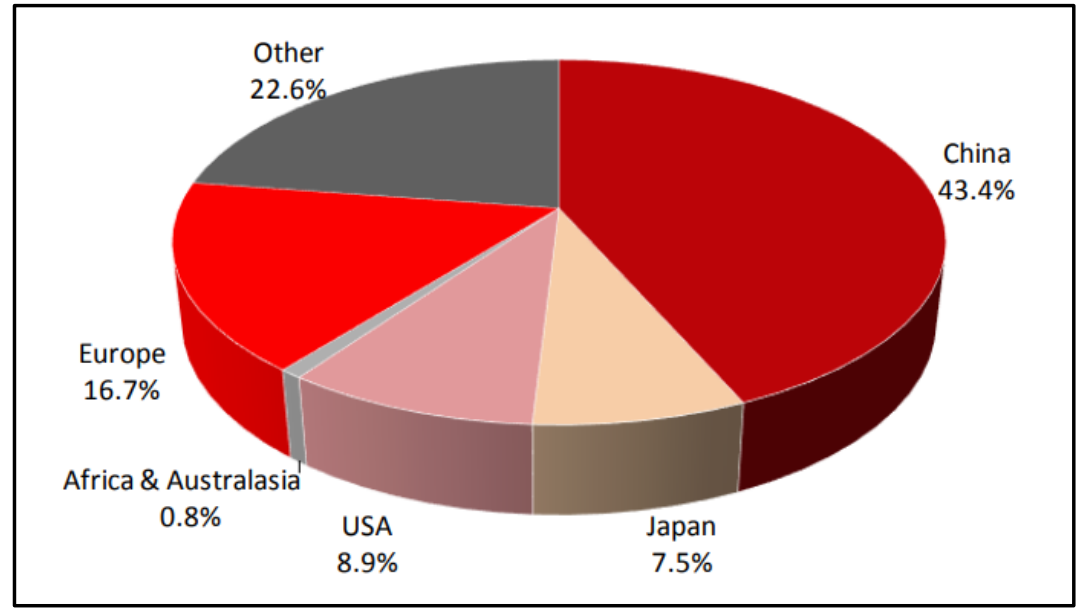

Sumber: ITRI, DBS Bank

Gambar 11. Grafik Presentase Negara Pengkonsumsi Timah 


\section{KESIMPULAN PENUTUP}

Harga komoditi logam timah, pada tahun 2019 mengalami penurunan dikarenakan adanya kecenderungan peningkatan produksi (oversupply). Indonesia sebagai negara eksportir terbesar ke2 di dunia seharusnya memiliki peluang untuk mengendalikan harga timah di dunia. Hilirisasi industri komoditas timah perlu ditingkatkan lagi agar produksi tambang komoditas timah dapat terserap untuk kebutuhan industri dalam negeri.

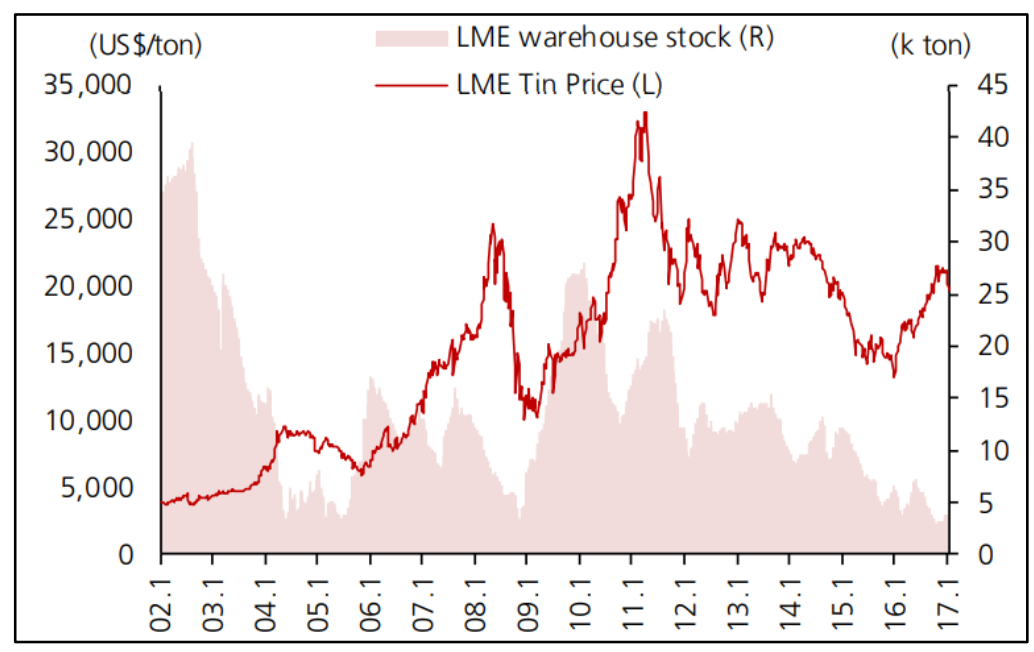

Sumber: Bloomberg Finance L.P., DBS Bank

Gambar 12. Grafik Perbandingan Harga Timah dengan Stock Produksi Timah Tahun 2017-2018

Upaya pelaksanaan konservasi mineral yang telah diterapkan oleh PT Timah, Tbk tentunya harus terus dilanjutkan sebagai wujud optimalisasi pengelolaan atau pemanfaatan sumber daya mineral secara terukur, efisien, bertanggung jawab, dan berkelanjutan. Hal ini terbukti dengan penerapan konservasi mineral, cadangan PT Timah Tbk mengalami peningkatan cukup signifikan. Perlu adanya upaya pemanfaatan dengan menyesuaikan teknologi yang ada untuk mineral ikutan sebagai produk samping PT. Timah, Tbk. Kerja sama antara Pemerintah khususnya Kementrian ESDM, Kementrian Lingkungan Hidup dan Kehutanan, serta Badan Tenaga Nuklir Nasional (BATAN) dengan PT Timah Tbk, perlu terus dikembangkan untuk terciptanya sebuah regulasi pemanfaatan mineral ikutan khususnya monasit yang diketahui merupakan salah satu mineral Rare Earth Element (REE) dan unsur radioaktif.

Pelaksanaan konservasi mineral dan batubara tentunya juga harus diterapkan oleh seluruh pelaku usaha pertambangan selain PT Timah, Tbk. Penerapan usaha konservasi tentunya akan membuat sumberdaya alam yang ada di Indonesia dapat dikelola dan dimanfaatkan secara terukur, efisien, bertanggung jawab, dan berkelanjutan untuk kesejahteraan seluruh bangsa Indonesia dan ketahanan nasional dari sektor sumberdaya alam.

\section{DAFTAR PUSTAKA}

PT Timah, Tbk, (2019): Rencana Kerja Anggaran dan Biaya Tahunan (RKAB) 2019 Wilayah Kep. Bangka Belitung

PT Timah, Tbk, (2019): Rencana Kerja Anggaran dan Biaya Tahunan (RKAB) 2019 Wilayah Kep. Riau dan Riau

PT Timah, Tbk, (2019): Laporan Berkala Konservasi Tahun 2019 Unit Produksi Wilayah Kep. Bangka Belitung 
PT Timah, Tbk, (2019): Laporan Berkala Konservasi Tahun 2019 Unit Produksi Wilayah Kep. Riau dan Riau

PT Timah, Tbk, (2019): Laporan Berkala Konservasi Tahun 2019 Unit Metalurgi Muntok

Badan Geologi Kementerian Energi Sumber Daya Mineral, (2018): Executive Summary Pemutakhiran Data dan Neraca Sumber Daya Mineral dan Batubara Status 2018

Data Produsen Timah di Dunia Tahun 2017-2018 dari U.S. Geological Survey, Mineral Commodity Summaries, February 2019, data diperoleh melalui situs internet: https://www.usgs.gov/centers/nmic/tin-statistics-and-information. Diunduh pada tanggal 10 September 2019.

Data Trend Harga Timah Tahun 2015-2019 dari @2019 The London Metal Exchange - an HKEX Company, data diperoleh melalui situs internet: https://www.lme.com/en-GB/Metals/Nonferrous/Tin\#tabIndex=0. Diunduh pada tanggal 16 September 2019.

Data Negara-Negara Pengkonsumsi Timah Tahun 2010-2015 dari DBS Group Research . Asian Insights Office, 22 Februari 2017, data diperoleh melalui situs internet: https://www.dbs.com/aics/pdfController.page?pdfpath=/content/article/pdf/000000_sectors/2 01702/COM_Tin_2017-02.pdf. Diunduh pada tanggal 16 September 2019. 